\title{
Effects of sitagliptin as initial therapy in newly diagnosed elderly type 2 diabetics: A randomized controlled study
}

\author{
XIAOYAN XIAO $^{1 *}$, XIAOPEI CUI $^{2 *}$, JIANBO ZHANG $^{3}$, ZHENXIA HAN $^{2}$, YU XIAO $^{2}$, \\ NAN CHEN ${ }^{2}$, BAOYING LI ${ }^{2}$, MEI CHENG ${ }^{2}$, HAIQING GAO ${ }^{2}$ and KUANXIAO TANG ${ }^{2}$ \\ Departments of ${ }^{1}$ Nephrology, ${ }^{2}$ Geriatrics and ${ }^{3}$ Emergency, Qilu Hospital of Shandong University, \\ Jinan, Shandong 250012, P.R. China
}

Received May 21, 2015; Accepted September 6, 2016

DOI: $10.3892 / \mathrm{etm} .2016 .3729$

\begin{abstract}
The objective of this study was to investigate the characteristics of blood glycemic excursion, incretins and pancreatic hormone secretion in elderly people with newly diagnosed type 2 diabetes mellitus (T2DM) and to study the effects of sitagliptin on glycemic excursion in these subjects. A total of 129 newly diagnosed T2DM patients were enrolled in the study from March 2012 to August 2013. Clinical data, serum incretin, pancreatic hormone and continuous glucose monitoring data were collected. Among these subjects, elderly patients (NEDM) randomly received metformin combined with sitagliptin phosphate or glimepiride for 24 weeks. The blood glucose, glycosylated hemoglobin $\mathrm{A}_{1 \mathrm{c}}\left(\mathrm{GHbA}_{1 \mathrm{c}}\right)$, serum incretins and pancreatic hormone levels were determined. During the oral glucose tolerance test (OGTT), 30 min insulin and C-peptide levels, $120 \mathrm{~min}$ insulin levels and ratio of the increases of insulin and blood glucose levels after $30 \mathrm{~min}$ of sugar loading $(\Delta \operatorname{Ins} 30 / \Delta$ Glu30) were significantly lower in elderly patients than in middle-aged patients $(\mathrm{P}<0.05)$. In addition, the glucagon elevation at $30 \mathrm{~min}$ was higher and the glucagon-like peptide-1 (GLP-1) at $30 \mathrm{~min}$ was lower in the elderly patients $(\mathrm{P}<0.05)$. Glucose excursion indices, including the standard deviation of the average blood glucose, intraday mean average glucose excursions (MAGE), and mean of daily differences (MODD), were significantly higher in the elderly patients $(\mathrm{P}<0.05)$. During the OGTT, insulin, $\mathrm{C}$-peptide and $\Delta$ Ins30/AGlu30 results at $30 \mathrm{~min}$ and GLP-1 levels at $120 \mathrm{~min}$ in NEDM subjects were significantly increased $(\mathrm{P}<0.05)$ and glucagon levels at $30 \mathrm{~min}$ was significantly lower after sitagliptin treatment $(\mathrm{P}<0.05)$ compared with glimepiride.
\end{abstract}

Correspondence to: Professor Kuanxiao Tang, Department of Geriatrics, Qilu Hospital of Shandong University, 107 Wenhuaxi Road, Jinan, Shandong 250012, P.R. China

E-mail: tkx610@hotmail.com

*Contributed equally

Key words: sitagliptin, elderly, type 2 diabetes, glycemic excursion, incretins
Moreover, MAGE and MODD were significantly lower in the sitagliptin group after treatment compared to those in the glimepiride group $(\mathrm{P}<0.05)$. No severe hypoglycemia or cardiovascular diseases were observed. Strong blood glucose excursions occur in elderly patients with newly diagnosed T2DM. Sitagliptin phosphate combined with metformin effectively and safely improves glycemic excursion and carbohydrate metabolism in NEDM patients by promoting the first phase of insulin and incretin secretion and inhibiting glucagon secretion of.

\section{Introduction}

The morbidity of type 2 diabetes mellitus (T2DM), particularly in elderly people, is increasing in China due to changes in lifestyle that have occurred in recent years. The prevalence of diabetes in individuals $>60$ years old is $\sim 20.4 \%(1,2)$. However, blood glycemic excursion (BGE) is poorly understood in this particular population.

Traditional treatment strategies for newly diagnosed elderly diabetics include one or more oral medications in addition to diet and exercise therapy, selected according to the level of blood glucose. Insulin injections remain the most potent therapy for uncontrolled T2DM. Multiple daily insulin injections can result in decreased variability of $24 \mathrm{~h}$ glucose levels (3) and delay the onset or progression of associated microvascular complications (4). However, hypoglycemia is a frequent side effect during insulin treatment, particularly in elderly patients. Sitagliptin, a dipeptidyl peptidase-4 (DPP-4) inhibitor, increases endogenous glucagon-like peptide 1 (GLP-1) secretion and improves $\beta$-cell function and glycemic excursions without inducing hypoglycemia in patients with T2DM (5,6). DPP-4 inhibitors provide a beneficial effect on body weight, episodes of hypoglycemia, and total adverse events as determined via meta-analysis (7). Furthermore, the effect of DPP-4 inhibitors on glycated hemoglobin $A_{1 c}$ $\left(\mathrm{GHbA}_{1 \mathrm{c}}\right)$ has been suggested to be greater in older adults than in younger adults with T2DM (8), which makes DPP-4 inhibitors a good choice for the clinical treatment of elderly patients with T2DM.

The present randomized case-controlled study was designed to examine the characteristics of glycemic excursion, incretins and pancreatic hormone secretion in elderly 
patients with newly diagnosed T2DM and to investigate the effects of sitagliptin on glycemic excursions in such patients.

\section{Materials and methods}

Subjects. A total of 129 patients newly diagnosed with T2DM from Qilu Hospital of Shandong University (Jinan, China) were enrolled in this study from March 2012 to August 2013. Inclusion criteria were as follows: i) Results from an oral glucose tolerance test in accordance with the standards set by the World Health Organization in 1999 (9) for patients with newly diagnosed T2DM; ii) aged between 45 and 80 years; iii) negative plasma glutamic acid decarboxylase antibody, islet cell antibody and insulin autoantibody test results; and iv) no previous use of hypoglycemic drugs. The exclusion criteria were as follows: i) Fasting blood glucose $>16.7 \mathrm{mmol} / 1$ or $\mathrm{GHbA}_{1 \mathrm{c}}>10 \%$; ii) acute diabetic complications such as ketoacidosis; iii) severe hepatic, renal, cerebral-cardiovascular or gastrointestinal co-morbidities; or iv) allergies to metformin hydrochloride, sitagliptin phosphate or glimepiride.

Patients were divided into two age groups: Aged $\geq 65$ years (NEDM group, $n=86$ ) and middle-aged group (45-65 years old; NMDM group, $n=43$ ). The elderly subjects were randomly assigned to receive sitagliptin phosphate (Januvia; Hangzhou MSD Pharmaceutical Co., Ltd., Hangzhou, China) combined with metformin (Glucophage; Sino-American Shanghai Squibb Pharmaceuticals Co., Ltd., Shanghai, China) and were defined as the SIG group or took glimepiride [Sanofi (Beijing) Pharmaceuticals Co., Ltd., Beijing, China] combined with metformin and were defined as the GLM group. The dose of sitagliptin was $100 \mathrm{mg}$ once daily, and the initial dose of glimepiride was $1 \mathrm{mg}$ once daily, and then titrated to $4 \mathrm{mg}$ once daily, according to the patient's glucose level. The initial dose of metformin was $0.25 \mathrm{~g}$ thrice daily and then increased to $0.5 \mathrm{~g}$ thrice daily according to the patient's glucose level. The study was approved by the institutional ethical review committee of Qilu Hospital of Shandong University (Approval ID: KLS12185), and informed written consent was obtained from each patient prior to participation.

Clinical and laboratory parameters. Clinical data including gender, age, height, weight, waist measurement, systolic blood pressure (SBP), diastolic blood pressure (DBP), body mass index (BMI) and past medical history were collected. Fasting fingertip blood glucose, $\mathrm{GHbA}_{1 c}$, total serum cholesterol (TC), triglyceride (TG), low-density lipoprotein-cholesterol (LDL-C), high-density lipoprotein-cholesterol (HDL-C) and uric acid (UA) levels were evaluated using fully automatic biochemical analysis instruments.

Continuous blood glucose monitoring. Subjects who agreed to use a blood glucose monitoring system (NEDM, $n=41$; NMDM, $n=21$ ) used a continuous glucose monitor (CGMS System Gold; Medtronic MiniMed, Inc., Northridge, CA, USA) for $72 \mathrm{~h}$. The patient maintained a normal amount of diet and exercise during monitoring to evaluate glucose variability. The fluctuant indices of glucose included mean blood glucose (MBG), standard deviation (SD) of the average blood glucose, intraday mean amplitude of glucose excursion
(MAGE), and mean of daily differences (MODD) of interday blood glucose.

Oral glucose tolerance test (OGTT) and pancreatic hormone measurements. An OGTT was performed at the beginning and end of the study. Serum glucose (glucose oxidase method) (10), insulin (chemiluminescence assay; \#03649928; Siemens Healthcare Diagnostics, Inc., Tarrytown, NY, USA), C-peptide (C-P; \#03649933; Siemens Healthcare Diagnostics, Inc.), glucagon [GLC enzyme-linked immunosorbent assay (ELISA); R\&D Systems, Inc., Minneapolis, MN, USA] and glucagon-like peptide-1 (GLP-1; ELISA; $R \& D$ Systems, Inc.) were evaluated at 0,30 and $120 \mathrm{~min}$ during the OGTT. The areas under the curve (AUC) for blood glucose, insulin, glucagon and GLP-1 were calculated using the following formula: $0.25 \times[(F X+(4 \times 30 \mathrm{~min} X)+$ $(3 \mathrm{x} 120 \mathrm{~min} \mathrm{X})]$. FX, $30 \mathrm{~min} \mathrm{X}$ and $120 \mathrm{~min} \mathrm{X}$ are the values of blood glucose at $0 \mathrm{~min}$, insulin at $30 \mathrm{~min}$, and glucagon or GLP-1 at $120 \mathrm{~min}$, respectively, during the OGTT. The homeostatic model assessment of $\beta$ cell function (HOMA- $\beta$ ) was calculated from fasting blood glucose (FBG) and fasting insulin (FINS; measured at 0 min during the OGTT) levels as follows: $20 \mathrm{x}$ FINS/(FBG - 3.5). HOMA-insulin resistance (HOMA-IR) was calculated as follows: (FBG x FINS)/22.5. The early phase of HOMA- $\beta$ was evaluated as the ratio of the net increments of insulin and blood glucose levels after 30 min of sugar loading: $\Delta \mathrm{Ins} 30 / \Delta \mathrm{Glu} 30(\Delta \mathrm{Ins} 30$ and $\Delta$ Glu30 are the increases in insulin and blood glucose levels, respectively, at $30 \mathrm{~min}$ of the OGTT) (11).

Follow-up visits. For the follow-up assessment, all patients were evaluated at the clinic at 4, 8, 12 and 24 weeks after enrollment. The follow-up visits were completed in all 129 patients. Blood glucose variation was measured using a fingertip micro blood glucose instrument, and treatment plans were adjusted according to the treatment guidelines for elderly patients with diabetic mellitus (12). Hypoglycemia was recorded. A self-monitored blood glucose level $<3.9 \mathrm{mmol} / \mathrm{l}$ was defined as hypoglycemia, and patients with hypoglycemic symptoms were defined as having symptomatic hypoglycemia, and those requiring management with emergency treatment were defined as having severe hypoglycemia. The onset and related hospitalization of severe cardiocerebral diseases including myocardial infarction, heart failure and stroke were also recorded.

Statistical analysis. Data are presented as the mean \pm SD. SPSS software (version 16.0; SPSS, Inc., Chicago, IL, USA) was used for all statistical analysis. Data from experiments were analyzed using Student's t-test or Chi-square tests, wherever appropriate. $\mathrm{P}<0.05$ was considered to indicate a statistically significant difference.

\section{Results}

Clinical parameters and blood glucose fluctuation in the NEDM and NMDM groups. As shown in Table I, age, SBP and LDL-C $(\mathrm{P}<0.05)$ levels were significantly different in the NEDM group compared with the NMDM group. There was no significant difference in other indices, including waist 

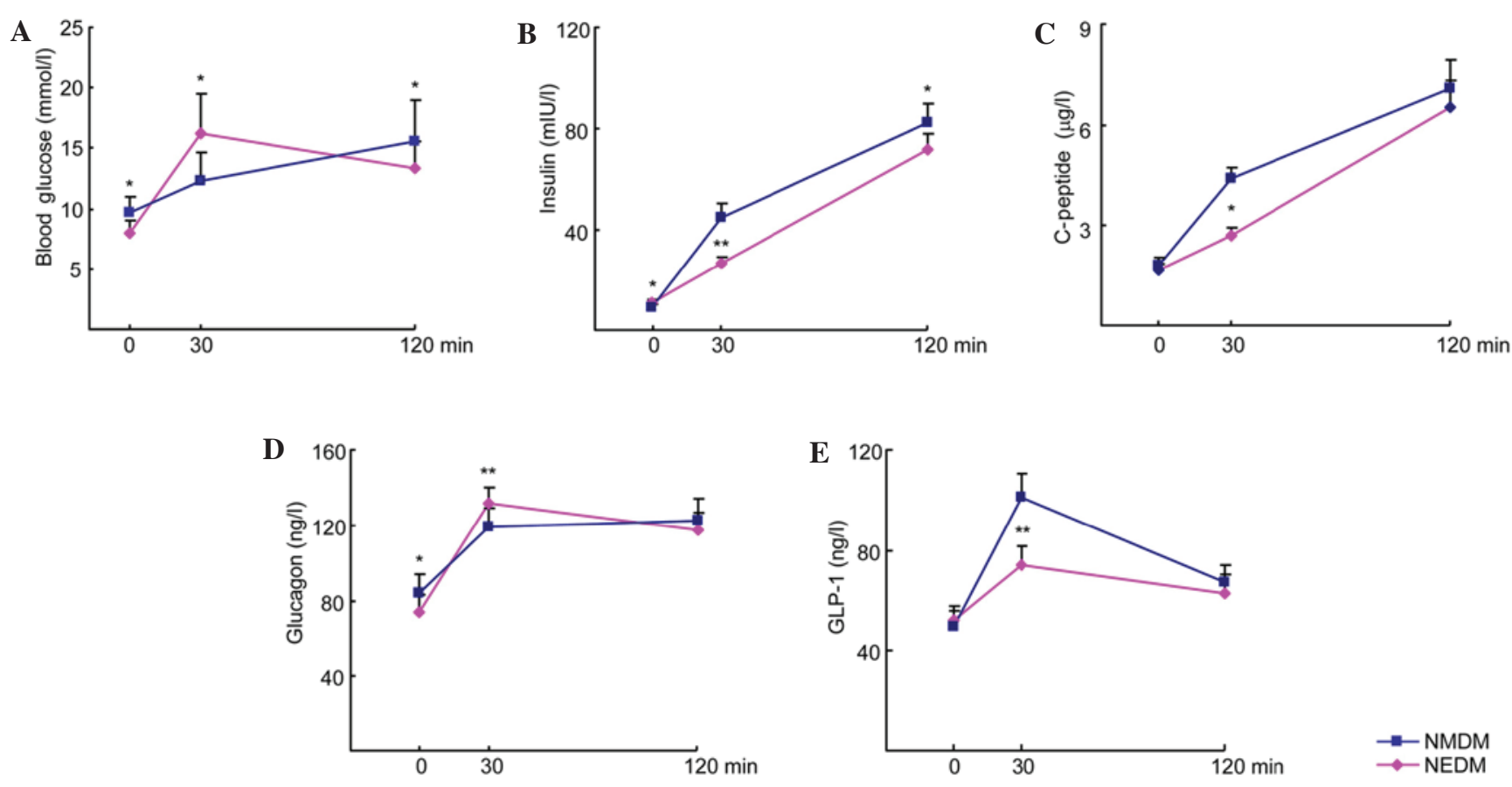

Figure 1. Glucose, incretins and pancreatic hormones during the OGTT in the two age groups at different time points. (A) Blood glucose levels,. (B) insulin levels, (C) C-peptide levels, (D) glucagon levels and (E) GLP-1 levels in the OGTT at 0,30 and 120 min. OGTT, oral glucose tolerance test; GLP-1, glucagonlike peptide-1; NMDM, middle-aged patients with diabetes mellitus (45-65 years old); NEDM, elderly patients with diabetes mellitus ( $\geq 65$ years old) ${ }^{*} \mathrm{P}<0.05$ and ${ }^{* *} \mathrm{P}<0.01$ vs. the NMDM group.

measurement, BMI, DBP and TG, TC, HDL-C and UA levels between the two groups.

Although the $\mathrm{GHbA}_{1 \mathrm{c}}$ levels were not different between the two groups ( $\mathrm{P}>0.05)$, the CGMS results showed that the FBG level in the NEDM group was slightly elevated, and the blood glucose level increased postprandially and then dropped sharply. Glycemic excursion parameters including the SD, MAGE and MODD in the NEDM group were greater than those in the NMDM group $(\mathrm{P}<0.05)$. However, the MBG of the two groups exhibited no significant difference (Table I).

Characteristics of incretins in the NEDM group. During the OGTT, blood glucose levels at 0 and 120 min were lower and those at $30 \mathrm{~min}$ were higher in the NEDM group compared with the NMDM group $(\mathrm{P}<0.05$; Fig. 1). The insulin levels at 0,30 and $120 \mathrm{~min}$ and the C-P and GLP-1 levels at $30 \mathrm{~min}$ were also lower in the NEDM group than in the NMDM group ( 8.09 vs $9.86 \mathrm{mIU} / \mathrm{L} ; \mathrm{P}<0.05$ ). The glucagon level at $0 \mathrm{~min}$ was lower and at 30 min higher in the NEDM group than in the NMDM group ( $\mathrm{P}<0.05$; Fig. 1). The $\mathrm{AUC}_{\mathrm{ins}}, \Delta \mathrm{Ins} 30 / \Delta \mathrm{Glu} 30$ and $\mathrm{AUC}_{\mathrm{glp}-1}$ in the NEDM group were lower than those the NMDM group $(\mathrm{P}<0.05$; Table II). These results indicate that the secretion of GLP-1 and insulin decreased in the early phase and was accompanied by increased secretion of glucagon by $\alpha$ cells during this time.

Effect of sitagliptin on glucose excursion and incretins in the NEDM group. No significant differences in clinical characteristics, $\mathrm{GHbA}_{1 \mathrm{C}}$ or CGMS glucose fluctuation indices were observed between the GLM and SIG groups prior to treatment ( $\mathrm{P}>0.05$; Table III). However, after 24 weeks of treatment, these parameters improved in both the SIG and GLM groups $(\mathrm{P}<0.05)$. Moreover, the MAGE and MODD in the SIG group were significantly lower compared with those in the GLM group $(\mathrm{P}<0.05$; Table IV).

No significant difference existed between the GLM and SIG groups for glucose, insulin, C-P, glucagon and GLP-1 during the OGTT prior to treatment $(\mathrm{P}>0.05)$. However, these parameters significantly improved in the two groups after treatment $(\mathrm{P}<0.05)$. Furthermore, with regard to OGTT results in the SIG group, the levels of insulin and C-P at $30 \mathrm{~min}$ and of GLP-1 at 0 and 30 min significantly increased $(\mathrm{P}<0.05)$, whereas the glucagon level at 30 min dropped sharply $(\mathrm{P}<0.01)$ compared with pre-treatment levels. In the GLM group, the levels of insulin and C-P at $120 \mathrm{~min}$ were significantly increased $(\mathrm{P}<0.05)$, whereas the glucagon and GLP-1 levels were maintained $(\mathrm{P}>0.05)$ compared with pre-treatment levels. In the SIG group post-treatment, glucose and glucagon levels at $30 \mathrm{~min}$ were lower compared with those in the GLM group $(\mathrm{P}<0.05)$, whereas insulin and GLP-1 levels at $30 \mathrm{~min}$ were higher compared with those in the GLM group $(\mathrm{P}<0.05$; Fig. 2).

As shown in Fig. 3, the AUCs for glucose, insulin, glucagon and GLP- 1 , and the HOMA- $\beta$, HOMA-IR and $\Delta$ Ins $30 / \Delta$ Glu 30 indices in the SIG and GLM groups were comparable prior to treatment $(\mathrm{P}>0.05)$. After treatment, all of these indices significantly improved in the SIG group $(\mathrm{P}<0.05)$, with the exception of the HOMA-IR. In the GLM group, the AUC for glucose significantly decreased $(\mathrm{P}<0.05)$, whereas the AUC for insulin, HOMA- $\beta$ and $\Delta$ Ins $30 / \Delta$ Glu30 significantly increased $(\mathrm{P}<0.05)$. In addition, the AUC for INS, GLP-1 and $\Delta \mathrm{Ins} 30 / \Delta \mathrm{Glu} 30$ in the SIG group were higher than those in the 
Table I. Clinical characteristics of the two age groups.

\begin{tabular}{|c|c|c|}
\hline Characteristics & NMDM & NEDM \\
\hline No. (M/F) & $43(23 / 20)$ & $86(45 / 41)$ \\
\hline Age (years) & $49.2 \pm 4.5$ & $68.6 \pm 5.2^{\mathrm{a}}$ \\
\hline BMI $\left(\mathrm{kg} / \mathrm{m}^{2}\right)$ & $27.80 \pm 3.16$ & $28.22 \pm 3.42$ \\
\hline Waist (cm) & $85.44 \pm 6.84$ & $87.03 \pm 7.18$ \\
\hline $\mathrm{SBP}(\mathrm{mmHg})$ & $130.7 \pm 14.6$ & $138.5 \pm 14.2^{b}$ \\
\hline DBP (mmHg) & $74.1 \pm 9.8$ & $72.4 \pm 10.5$ \\
\hline TG (mmol/l) & $2.62 \pm 0.60$ & $2.47 \pm 0.66$ \\
\hline $\mathrm{TC}(\mathrm{mmol} / \mathrm{l})$ & $5.82 \pm 2.01$ & $5.68 \pm 1.53$ \\
\hline HDL-C (mmol/l) & $1.28 \pm 0.55$ & $1.14 \pm 0.42$ \\
\hline LDL-C (mmol/1) & $3.51 \pm 0.53$ & $4.43 \pm 0.67^{b}$ \\
\hline $\mathrm{UA}(\mu \mathrm{mol} / \mathrm{l})$ & $390.75 \pm 91.05$ & $383.06 \pm 75.29$ \\
\hline $\mathrm{GHbA}_{1 \mathrm{c}}(\%)$ & $7.59 \pm 1.60$ & $7.21 \pm 1.24$ \\
\hline $\operatorname{MBG}(\mathrm{mmol} / \mathrm{l})^{\mathrm{c}}$ & $11.03 \pm 0.52$ & $12.16 \pm 0.35$ \\
\hline $\mathrm{SD}(\mathrm{mmol} / \mathrm{l})^{\mathrm{c}}$ & $1.85 \pm 0.12$ & $3.29 \pm 0.17^{\mathrm{a}}$ \\
\hline $\operatorname{MAGE}(\mathrm{mmol} / \mathrm{l})^{\mathrm{c}}$ & $4.83 \pm 0.25$ & $8.06 \pm 0.38^{\mathrm{a}}$ \\
\hline $\operatorname{MODD}(\mathrm{mmol} / \mathrm{l})^{\mathrm{c}}$ & $1.70 \pm 0.06$ & $2.62 \pm 0.08^{\mathrm{b}}$ \\
\hline \multicolumn{3}{|c|}{$\begin{array}{l}\text { BMI, body mass index; SBP, systolic blood pressure; DBP, dia- } \\
\text { stolic blood pressure; TG, triglyceride; TC, total cholesterol; } \\
\text { HDL-C, high-density lipoprotein-cholesterol; LDL-C, low-density } \\
\text { lipoprotein-cholesterol; UA, uric acid; } \mathrm{GHbA}_{1 \mathrm{c}} \text {, glycosylated hemo- } \\
\text { globin } \mathrm{A}_{1 \mathrm{c}} \text {; MBG, mean blood glucose; SD, standard deviation; } \\
\text { MAGE, mean average blood glucose excursions; MODD, mean of } \\
\text { daily differences; } \mathrm{M} \text {, male; F, female; NMDM, middle-aged patients } \\
\text { with diabetes mellitus ( } 45-65 \text { years old); NEDM, elderly patients } \\
\text { with diabetes mellitus ( } \geq 65 \text { years old). }{ }^{\mathrm{a}}<0.01 \text { and }{ }^{\mathrm{b}} \mathrm{P}<0.05 \text { vs. the } \\
\text { NMDM group. }{ }^{\mathrm{c}} \mathrm{Number} \text { of cases using a continuous glucose monitor: } \\
\text { NEDM group, } \mathrm{n}=41 ; \text { NMDM group, } \mathrm{n}=21 \text {. }\end{array}$} \\
\hline
\end{tabular}

Table II. AUCs and indices of the two age groups.

\begin{tabular}{lcc}
\hline Variable & NMDM & NEDM \\
\hline AUC $_{\text {BG }}$ & $26.75 \pm 2.42$ & $28.64 \pm 2.75$ \\
AUC $_{\text {Ins }}$ & $107.27 \pm 9.20$ & $82.33 \pm 7.26^{\mathrm{a}}$ \\
$\mathrm{AUC}_{\mathrm{Glc}}$ & $324.61 \pm 30.33$ & $335.28 \pm 36.59$ \\
$\mathrm{AUC}_{\mathrm{GLP}-1}$ & $169.11 \pm 15.46$ & $139.52 \pm 14.07^{\mathrm{a}}$ \\
$\mathrm{HOMA} \beta$ & $37.05 \pm 3.20$ & $41.02 \pm 3.76$ \\
$\mathrm{HOMA}-\mathrm{IR}$ & $3.48 \pm 0.25$ & $3.54 \pm 0.26$ \\
$\Delta$ Ins30/ $\Delta$ Glu30 & $7.15 \pm 0.58$ & $2.88 \pm 0.22^{\mathrm{b}}$ \\
\hline
\end{tabular}

AUC, area under the curve; BG, blood glucose; Ins, insulin; Glc, glucagon; GLP-1, glucagon-like peptide-1; HOMA- $\beta$, homeostatic model assessment of $\beta$ cell function; HOMA-IR, HOMA-insulin resistance; $\Delta \mathrm{Ins} 30 / \Delta \mathrm{Glu} 30$, ratio of increments of insulin and blood glucose levels after 30 min of sugar loading; NMDM, middle-aged patients with diabetes mellitus (45-65 years old; $n=43$ ); NEDM, elderly patients with diabetes mellitus ( $\geq 65$ years old; $n=86$ ). ${ }^{a} \mathrm{P}<0.05$ and ${ }^{\mathrm{b}} \mathrm{P}<0.01$ vs. the NMDM group.

GLM group following treatment $(\mathrm{P}<0.05)$, whereas the AUC for glucagon was lower $(\mathrm{P}<0.05)$.
Table III. Clinical characteristics of the GLM and SIG groups of NEDM subjects at baseline.

\begin{tabular}{lcc}
\hline Variable & GLM group & SIG group \\
\hline No. $(\mathrm{M} / \mathrm{F})$ & $18(10 / 8)$ & $23(13 / 10)$ \\
Age $($ years $)$ & $69.1 \pm 6.5$ & $68.7 \pm 6.3$ \\
BMI $\left(\mathrm{kg} / \mathrm{m}^{2}\right)$ & $27.92 \pm 3.87$ & $28.34 \pm 3.81$ \\
Waist $(\mathrm{cm})$ & $87.81 \pm 7.67$ & $88.16 \pm 7.66$ \\
SBP $(\mathrm{mmHg})$ & $137.3 \pm 13.6$ & $139.7 \pm 14.1$ \\
DBP $(\mathrm{mmHg})$ & $71.8 \pm 10.5$ & $72.5 \pm 10.8$ \\
TG $(\mathrm{mmol} / \mathrm{l})$ & $2.55 \pm 0.71$ & $2.39 \pm 0.69$ \\
TC $(\mathrm{mmol} / \mathrm{l})$ & $5.87 \pm 1.64$ & $5.59 \pm 1.65$ \\
HDL-C $(\mathrm{mmol} / \mathrm{l})$ & $1.09 \pm 0.37$ & $1.16 \pm 0.46$ \\
LDL-C $(\mathrm{mmol} / \mathrm{l})$ & $4.18 \pm 0.49$ & $4.53 \pm 0.64$ \\
UA $(\mu \mathrm{mol} / \mathrm{l})$ & $381.56 \pm 74.37$ & $385.44 \pm 76.22$ \\
\hline
\end{tabular}

GLM group, patients treated with glimepiride and metformin; SIG group, patients treated with sitagliptin and metformin; NEDM, elderly patients with diabetes mellitus ( $\geq 65$ years old); M, male; F, female; BMI, body mass index; SBP, systolic blood pressure; DBP, diastolic blood pressure; TG, triglyceride; TC, total cholesterol; HDL-C, high-density lipoprotein-cholesterol; LDL-C, low-density lipoprotein-cholesterol; UA, uric acid.

Other effects. The average body weight significantly decreased in the SIG group following treatment $(78.2 \pm 4.5 \mathrm{~kg}$ at baseline vs. $75.8 \pm 4.0 \mathrm{~kg}$ at the end of treatment; $\mathrm{P}<0.05)$, whereas there was no significant change in the average body weight $(79.0 \pm 4.6 \mathrm{~kg}$ at baseline vs. $78.1 \pm 4.3 \mathrm{~kg}$ at the end of treatment; P>0.05) in the GLM group. The body weights were significantly different in the SIG group compared with the GLM group at the end of treatment $(\mathrm{P}<0.05)$. The incidence of symptomatic hypoglycemia in the SIG and GLM groups was 2.9 and $4.7 \%$, respectively $(\mathrm{P}<0.05)$. No severe hypoglycemia was observed in any subject.

No myocardial infarction, heart failure, and stroke occurred during the follow up.

\section{Discussion}

The amplitude of glucose variability increases from subjects with normal glucose tolerance (NGT) to those in patients with T2DM. When compared with individuals with NGT and impaired glucose regulation, subjects with NMDM show more predominant intra- and interday glucose variability and postprandial glucose excursion (13). However, to the best of our knowledge, there has been no case-control study regarding the characteristics of glycemic excursion in NEDM patients. In the present study, glucose variability was observed as a slight increase in FBG level and a sharp increase in the postprandial glucose level in NEDM patients. The CGMS glucose excursion parameters such as MAGE and MODD were also observed to increase and exhibited extreme fluctuations.

The feature of glucose fluctuation in T2DM is closely associated with the number and function of $\beta$ cells and the secretion level and function of insulin, glucagon and GLP-1. Previous studies have already verified that aging has a 
Table IV. Glucose excursion parameters between the SIG and GLM groups.

\begin{tabular}{lrrrr}
\hline & \multicolumn{2}{c}{ GLM group } & \multicolumn{2}{c}{ SIG group } \\
\cline { 2 - 3 } Parameter & Pretreatment & After treatment & & Pretreatment \\
\hline GHbA $_{1 \mathrm{c}}(\%)$ & $7.27 \pm 1.15$ & $6.47 \pm 0.70^{\mathrm{a}}$ & $7.32 \pm 1.01$ & $6.25 \pm 0.62^{\mathrm{a}}$ \\
MBG $(\mathrm{mmol} / \mathrm{l})$ & $11.89 \pm 1.12$ & $8.82 \pm 0.85^{\mathrm{a}}$ & $12.16 \pm 1.35$ & $8.35 \pm 0.79^{\mathrm{b}}$ \\
$\mathrm{SD}(\mathrm{mmol} / \mathrm{l})$ & $3.18 \pm 0.45$ & $1.63 \pm 0.23^{\mathrm{a}}$ & $3.29 \pm 0.47$ & $1.57 \pm 0.21^{\mathrm{a}}$ \\
MAGE $(\mathrm{mmol} / \mathrm{l})$ & $8.27 \pm 1.21$ & $6.01 \pm 0.77^{\mathrm{a}}$ & $8.06 \pm 1.18$ & $4.42 \pm 0.46^{\mathrm{b}, \mathrm{c}}$ \\
MODD $(\mathrm{mmol} / \mathrm{l})$ & $3.70 \pm 0.46$ & $2.63 \pm 0.37^{\mathrm{a}}$ & $3.62 \pm 0.48$ & $1.74 \pm 0.21^{\mathrm{a}, \mathrm{d}}$ \\
\hline
\end{tabular}

GLM, treated with glimepiride and metformin ( $\mathrm{n}=18,10 \mathrm{M}$ and $8 \mathrm{~F}$ ); SIG, treated with sitagliptin and metformin ( $\mathrm{n}=23,13 \mathrm{M}$ and $10 \mathrm{~F})$; $\mathrm{GHbA}_{1 \mathrm{c}}$, glycosylated hemoglobin $\mathrm{A}_{1 \mathrm{c}}$; MBG, mean blood glucose; SD, standard deviation; MAGE, mean average blood glucose excursions; MODD, mean of daily differences; $\mathrm{M}$, male; $\mathrm{F}$, female. ${ }^{\mathrm{a}} \mathrm{P}<0.05$ and ${ }^{\mathrm{b}} \mathrm{P}<0.01$ vs. pretreatment; ${ }^{\mathrm{c}} \mathrm{P}<0.01$ and ${ }^{\mathrm{d}} \mathrm{P}<0.05$ vs. the GLM group.
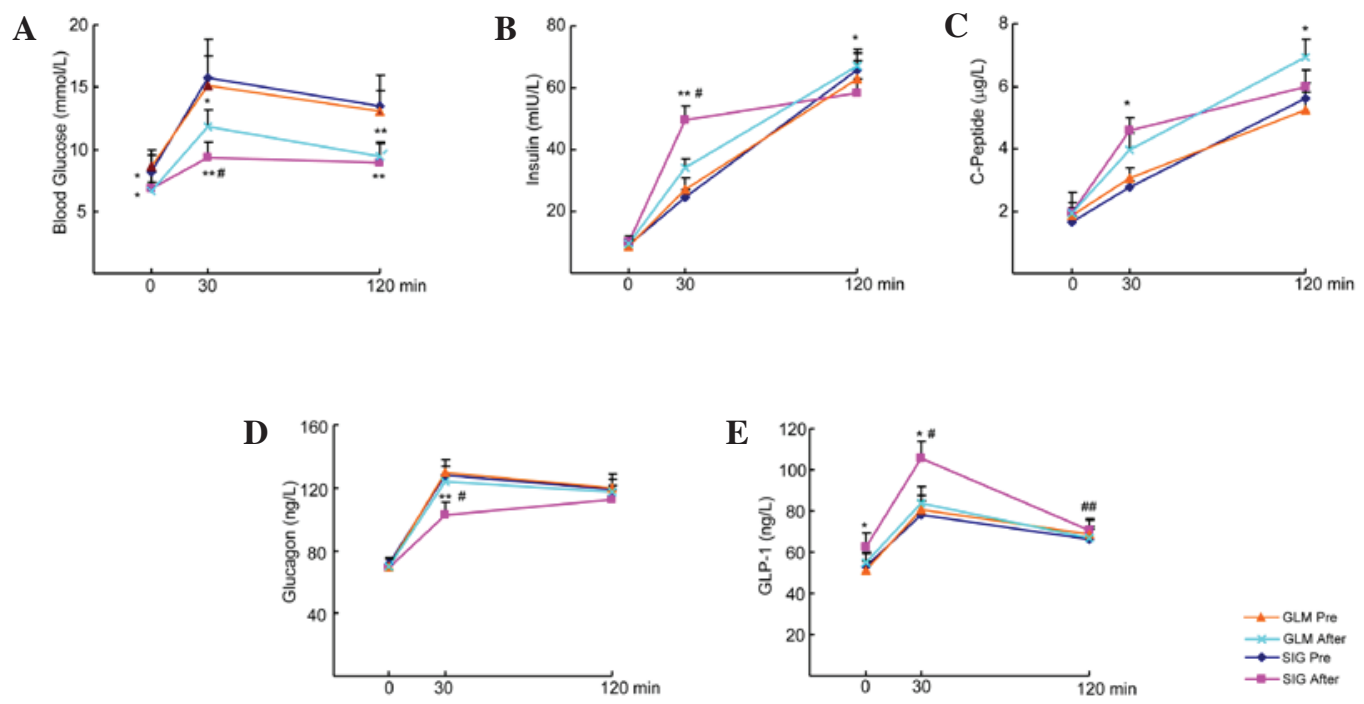

Figure 2. Glucose, incretins and pancreatic hormones during the OGTT before (Pre) and after sitagliptin (SIG) or glimepiride (GLM) treatment. (A) Blood glucose, (B) insulin, (C) C-peptide, (D) glucagon and (E) GLP-1 levels during the OGTT were measured in the SIG and GLM groups before and after treatment. OGTT, oral glucose tolerance test; GLP-1, glucagon-like peptide-1. ${ }^{*} \mathrm{P}<0.05$ and ${ }^{* *} \mathrm{P}<0.01$ vs. pre-treatment; $\mathrm{P}<0.05$ and ${ }^{\# \#} \mathrm{P}<0.01$ vs. the GLM group.

negative effect on islet function $(14,15)$. In hyperglycemic clamp experiments, first and second phase insulin secretion in people with NGT normally decrease by $0.7 \%$ per year, with a greater reduction in the first phase compared with the second phase (16). A study involving Chinese individuals with NGT also demonstrate that insulin secretion and the ability of islets to compensate decrease with age for basal glucose levels and after oral glucose loading (17). Age-related IGT in healthy elderly people is not caused by a reduction in $\beta$ cell number but rather the secretion and function of insulin (18), as $\beta$ cells in all age groups including healthy, aged and very aged remain stable $(19,20)$. Patients with IGT and elderly diabetes mellitus (EDM) subjects have a 40 and $50 \%$ deficit, respectively, in the number of $\beta$ cells compared with those in healthy controls $(21,22)$. This deficit results from decreased proliferation and replication along with increased apoptosis and necrosis of $\beta$ cells with aging (20). However, $\beta$ cell secretion in EDM patients gradually decreases as diabetes mellitus progresses, with urinal C-P decreasing 6\% per year (23). Glucagon and GLP-1 secretion levels in the early phase for EDM patients remain unclear. In the present study, the $\Delta \mathrm{Ins} 30 / \Delta \mathrm{Glu} 30$, and the $\mathrm{AUC}_{\text {Ins }}$ and GLP-1 level at 30 min were lower in the NEDM group than in the NMDM group, and the glucagon level increased at $30 \mathrm{~min}$ in the NEDM group. These results indicate that the synthesis of glycogen by the liver significantly decreases under the action of insulin, whereas the breakdown of liver glycogen into glucose is accelerated by glucagon, resulting in the highly undulating glycemic excursions in NEDM subjects. The results of the present study demonstrate that aging impairs GLP-1 secretion, which contributes to high post-prandial glycemia, and these data are in accordance with results of a recent study (24).

DPP-4 inhibitors and sulfonylureas are important second-line anti-diabetic agents used with metformin or as a monotherapy. DPP-4 degrades endogenous GLP-1 following its secretion. Sitagliptin is a highly selective DPP-4 inhibitor that inhibits $\geq 80 \%$ of plasma DPP- 4 activity and augments the level of active GLP-1 following an OGTT (5). Animal experiments have indicated that GLP-1 reduces $\beta$ cell apoptosis, improves $\beta$ cell replication and regeneration, and inhibits $\alpha$ cell oversecretion (25). A clinical study has found that sitagliptin phosphate used as a monotherapy or in combi- 

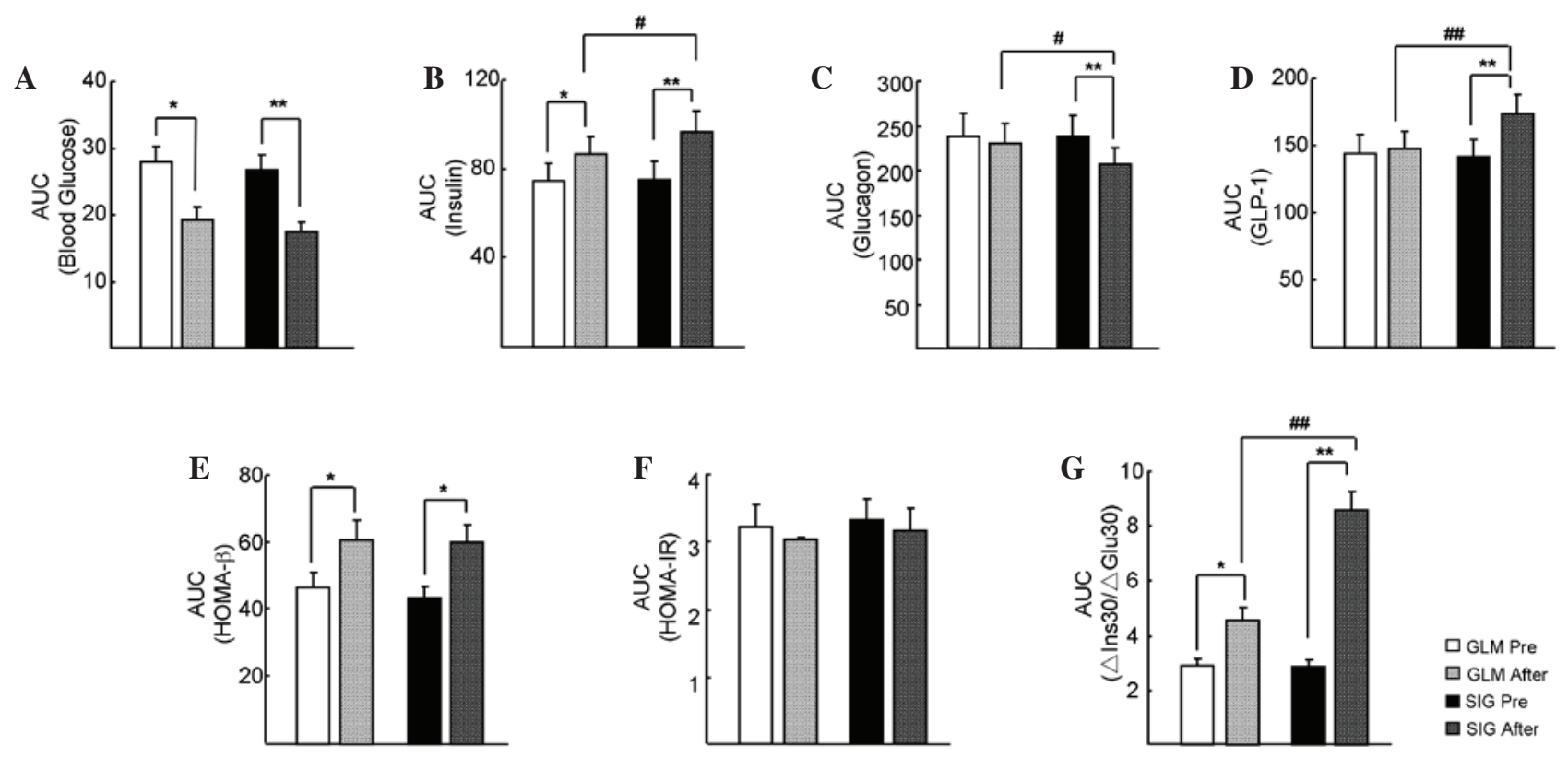

Figure 3. Area under the curve (AUC) comparisons during the OGTT after sitagliptin (SIG) or glimepiride (GLM) treatment. (A) Glucose, (B) serum insulin, (C) C-peptide and (D) GLP-1 AUCs were analyzed at different time points during the OGTT. (D) The AUC of GLP-1 was significantly increased after SIG treatment, but not after GLM treatment. (E) The SIG and GLM groups showed similar increases in HOMA- $\beta$ AUC during treatment, with no significant difference between groups. (F) Neither sitagliptin nor glimepiride affected the HOMA-IR. (G) The AUC of $\Delta$ Ins30/AGlu30 increased in the two groups, although a greater increase occurred in the SIG group. OGTT, oral glucose tolerance test; GLP-1, glucagon-like peptide-1; HOMA- $\beta$, homeostatic model assessment of $\beta$ cell function; HOMA-IR, HOMA-insulin resistance; $\Delta$ Ins30/ $\Delta$ Glu30, ratio of increments of insulin and blood glucose levels after 30 min of sugar loading. ${ }^{*} \mathrm{P}<0.05$ and ${ }^{* *} \mathrm{P}<0.01$ vs. pre-treatment; ${ }^{*} \mathrm{P}<0.05$ and ${ }^{\# \#} \mathrm{P}<0.01$ vs. the GLM group.

nation with other antidiabetic drugs can help improve GLP-1 secretion and $\beta$ cell function, resulting in improved glycemic control (26). Rauch et al administered a 7-week monotherapy of linagliptin to T2DM subjects aged from 18 to 80 years and found that the treatment significantly increased the GLP-1 level, suppressed glucagon and improved the FBG and $\mathrm{HbA}_{1 \mathrm{c}}$ levels (27). In the present study, after 24 weeks of metformin combined with sitagliptin phosphate treatment in the NEDM group, it was found that insulin secretion in the early phase and GLP-1 secretion was improved, and the abnormal secretion of glucagon was suppressed. However, metformin combined with glimepiride did not change the GLC and GLP-1 levels, suggesting that the combination of metformin with sitagliptin phosphate has a synergistic effect for the treatment of NEDM.

In a previous study, the FBG and $2 \mathrm{~h}$ postprandial blood glucose levels in newly diagnosed NEDM subjects decreased after 24 weeks of sitagliptin monotherapy (6). Sitagliptin monotherapy treatment significantly and rapidly improves glycemic measures and is well tolerated in patients with T2DM aged $\geq 65$ years (28). In the present study, sitagliptin improved early phase insulin secretion and GLP-1 levels and suppressed the reverse secretion of $\alpha$ cells in the NEDM group. Increased early phase insulin secretion promotes glucose intake and metabolism in cells while increased serum GLP-1 may improve the early phase secretion of $\beta$ cells in NEDM patients.

Notably, a recent study has shown that glucose fluctuations during the acute phase of acute myocardial infarction affect the myocardial salvage index (MSI), and the plasma GLP-1 level is positively correlated with the MSI. Since coronary artery diseases (CADs) are common in elderly people with
T2DM, this finding indicates that patients with CAD may obtain greater benefits after sitagliptin treatment (29).

Animal experiments and clinical research have found that the hypoglycemic effect of sitagliptin presents glucose dependence $(30,31)$. Notably, the prevalence of cerebral-cardiovascular disease in EDM patients is much higher than in other groups (32), so safety is particularly important. There are previous reports concerning the association of sitagliptin with heart failure $(33,34)$, however, in the present study, no severe cardiovascular diseases occurred. This study demonstrates that the combination of metformin with sitagliptin is a relatively safe treatment for NEDM patients.

This study has several limitations. First, the sample size was low. Second, not all subjects underwent continuous blood glucose monitoring due to the cost of this system. Third, this study was a small-size clinical observation, and the mechanism was not investigated. More studies are required to explain the underlying mechanism.

In conclusion, in NEDM patients, blood glucose fluctuations occur due to defects in the first phase of insulin and incretin secretion and the excessive secretion of glucagon by pancreatic $\alpha$ cells. Sitagliptin phosphate combined with metformin effectively and safely improves glycemic excursion and carbohydrate metabolism in NEDM patients by promoting the first phase of insulin and incretin secretion and inhibiting the secretion of glucagon.

\section{Acknowledgements}

This study was supported by grants from special funds for scientific research projects of clinical medicine of the Chinese Medical Association (grant no. 13060990484), the Medicine 
Health Care Science and Technology Development Project Program of Shandong Province (grant no. 2013WSC02036), Science Foundation of Qilu Hospital of Shandong University (grant no. 2015QLMS11) and Fundamental Research Funds of Shandong University (26010175616012).

\section{References}

1. Yang W, Lu J, Weng J, Jia W, Ji L, Xiao J, Shan Z, Liu J, Tian H, $\mathrm{Ji}$ Q, et al: Prevalence of diabetes among men and women in China. N Engl J Med 362: 1090-1101, 2010.

2. Xu Y, Wang L, He J, Bi Y, Li M, Wang T, Wang L, Jiang Y, Dai M, Lu J, et al: Prevalence and control of diabetes in Chinese adults. JAMA 310: 948-959, 2013.

3. Testa MA, Gill J, Su M, Turner RR, Blonde L and Simonson DC: Comparative effectiveness of basal-bolus vs. premix analog insulin on glycemic variability and patient-centered outcomes during insulin intensification in type 1 and type 2 diabetes: A randomized, controlled, crossover trial. J Clin Endocrinol Metab 97: 3504-3514, 2012.

4. Wake N, Hisashige A, Katayama T, Kishikawa H, Ohkubo Y, Sakai M, Araki E and Shichiri M: Cost-effectiveness of intensive insulin therapy for type 2 diabetes: A 10-year follow-up of the Kumamoto study. Diabetes Res Clin Pract 48: 201-210, 2000.

5. Herman GA, Bergman A, Stevens C, Kotey P, Yi B, Zhao P, Dietrich B, Golor G, Schrodter A, Keymeulen B, et al: Effect of single oral doses of sitagliptin, a dipeptidyl peptidase-4 inhibitor, on incretin and plasma glucose levels after an oral glucose tolerance test in patients with type 2 diabetes. J Clin Endocrinol Metab 91: 4612-4619, 2006

6. Rosenstock J, Aguilar-Salinas C, Klein E, Nepal S, List J and Chen R: Effect of saxagliptin monotherapy in treatment-naive patients with type 2 diabetes. Curr Med Res Opin 25: 2401-2411, 2009.

7. Zhang Y, Hong J, Chi J, Gu W, Ning G and Wang W: Head-to-head comparison of dipeptidyl peptidase-IV inhibitors and sulfonylureas - a meta-analysis from randomized clinical trials. Diabetes Metab Res Rev 30: 241-256, 2013.

8. Monami M, Cremasco F, Lamanna C, Marchionni N and Mannucci E: Predictors of response to dipeptidyl peptidase-4 inhibitors: Evidence from randomized clinical trials. Diabetes Metab Res Rev 27: 362-372, 2011.

9. Gabir MM, Hanson RL, Dabelea D, Imperatore G, Roumain J, Bennett PH and Knowler WC: Plasma glucose and prediction of microvascular disease and mortality: Evaluation of 1997 American Diabetes Association and 1999 World Health Organization criteria for diagnosis of diabetes. Diabetes Care 23: $1113-1118,2000$.

10. Lott JA and Turner K: Evaluation of Trinder's glucose oxidase method for measuring glucose in serum and urine. Clin Chem 21: $1754-1760,1975$.

11. Bonora E, Targher G, Alberiche M, Bonadonna RC, Saggiani F Zenere MB, Monauni T and Muggeo M: Homeostasis model assessment closely mirrors the glucose clamp technique in the assessment of insulin sensitivity: Studies in subjects with various degrees of glucose tolerance and insulin sensitivity. Diabetes Care 23: 57-63, 2000.

12. Tuerk PW, Mueller M and Egede LE: Estimating physician effects on glycemic control in the treatment of diabetes: Methods, effects sizes and implications for treatment policy. Diabetes Care 31: 869-873, 2008

13. Wang C, Lv L, Yang Y, Chen D, Liu G, Chen L, Song Y, He L, Li X, Tian H, et al: Glucose fluctuations in subjects with normal glucose tolerance, impaired glucose regulation and newly diagnosed type 2 diabetes mellitus. Clin Endocrinol (Oxf) 76: 810-815, 2012.

14. Cnop M, Igoillo-Esteve M, Hughes SJ, Walker JN, Cnop I and Clark A: Longevity of human islet $\alpha$-and $\beta$-cells. Diabetes Obes Metab (13 Suppl 1): 39-46, 2011.

15. Cnop M, Hughes SJ, Igoillo-Esteve M, Hoppa MB, Sayyed F, van de Laar L, Gunter JH, de Koning EJ, Walls GV, Gray DW, et al: The long lifespan and low turnover of human islet beta cells estimated by mathematical modelling of lipofuscin accumulation. Diabetologia 53: 321-330, 2010.

16. Szoke E, Shrayyef MZ, Messing S, Woerle HJ, van Haeften TW, Meyer C, Mitrakou A, Pimenta W and Gerich JE: Effect of aging on glucose homeostasis: Accelerated deterioration of beta-cel function in individuals with impaired glucose tolerance. Diabetes Care 31: 539-543, 2008.
17. Zhu HQ, Yang ZJ, Zhang B, Xiao JZ and Yang WY: Ageing related changes of insulin secretion and insulin sensitivity among normal glucose tolerance individuals in China. Zhonghua Yi Xue Za Zhi 92: 1948-1953, 2012 (In Chinese).

18. Basu R, Breda E, Oberg AL, Powell CC, Dalla Man C, Basu A, Vittone JL, Klee GG, Arora P, Jensen MD, et al: Mechanisms of the age-associated deterioration in glucose tolerance: Contribution of alterations in insulin secretion, action and clearance. Diabetes 52: 1738-1748, 2003.

19. Saisho Y, Butler AE, Manesso E, Elashoff D, Rizza RA and Butler PC: $\beta$-cell mass and turnover in humans: Effects of obesity and aging. Diabetes Care 36: 111-117, 2013.

20. Kushner JA: The role of aging upon $\beta$ cell turnover. J Clin Invest 123: 990-995, 2013.

21. Butler AE, Janson J, Bonner-Weir S, Ritzel R, Rizza RA and Butler PC: Beta-cell deficit and increased beta-cell apoptosis in humans with type 2 diabetes. Diabetes 52: 102-110, 2003.

22. Maclean N and Ogilvie RF: Quantitative estimation of the pancreatic islet tissue in diabetic subjects. Diabetes 4: 367-376, 1955.

23. Bushhouse SA, Goetz FC, Jacobs DR Jr, Bender AP, French LR, Oestreich PG and Geisser MS: C-peptide response to meal challenge in nondiabetic and diabetic adults living in Wadena, Minnesota. Diabetes Care 15: 1335-1347, 1992.

24. Geloneze B, de Oliveira Mda S, Vasques AC, Novaes FS, Pareja JC and Tambascia MA: Impaired incretin secretion and pancreatic dysfunction with older age and diabetes. Metabolism 63: 922-929, 2014.

25. Stoffers DA, Kieffer TJ, Hussain MA, Drucker DJ, Bonner-Weir S, Habener JF and Egan JM: Insulinotropic glucagon-like peptide 1 agonists stimulate expression of homeodomain protein IDX-1 and increase islet size in mouse pancreas. Diabetes 49: 741-748, 2000.

26. Solis-Herrera C, Triplitt C, Garduno-Garcia Jde J, Adams J, DeFronzo RA and Cersosimo E: Mechanisms of glucose lowering of dipeptidyl peptidase-4 inhibitor sitagliptin when used alone or with metformin in type 2 diabetes: A double-tracer study. Diabetes Care 36: 2756-2762, 2013.

27. Rauch T, Graefe-Mody U, Deacon CF, Ring A, Holst JJ, Woerle HJ, Dugi KA and Heise T: Linagliptin increases incretin levels, lowers glucagon and improves glycemic control in type 2 diabetes mellitus. Diabetes Ther 3: 10, 2012.

28. Barzilai N, Guo H, Mahoney EM, Caporossi S, Golm GT, Langdon RB, Williams-Herman D, Kaufman KD, Amatruda JM, Goldstein BJ and Steinberg H: Efficacy and tolerability of sitagliptin monotherapy in elderly patients with type 2 diabetes: A randomized, double-blind, placebo-controlled trial. Curr Med Res Opin 27: 1049-1058, 2011.

29. Teraguchi I, Imanishi T, Ozaki Y, Tanimoto T, Ueyama M, Orii M, Shiono Y, Shimamura K, Ishibashi K, Yamano T, et al: Acute-phase glucose fluctuation is negatively correlated with myocardial salvage after acute myocardial infarction. Circ J 78: 170-179, 2014.

30. Takihata M, Nakamura A, Tajima K, Inazumi T, Komatsu Y, Tamura H, Yamazaki S, Kondo Y, Yamada M, Kimura M and Terauchi Y: Comparative study of sitagliptin with pioglitazone in Japanese type 2 diabetic patients: The COMPASS randomized controlled trial. Diabetes Obes Metab 15: 455-462, 2013.

31. Meyre D, Froguel P, Horber FF and Kral JG: Comment on: Valette et al. Melanocortin-4 receptor mutations and polymorphisms do not affect weight loss after bariatric surgery. PLoS One 9: e93324, 2014.

32. Alexander CM, Landsman PB, Teutsch SM and Haffner SM; Third National Health and Nutrition Examination Survey (NHANES III); National Cholesterol Education Program (NCEP): NCEP-defined metabolic syndrome, diabetes, and prevalence of coronary heart disease among NHANES III participants age 50 years and older. Diabetes 52: 1210-1214, 2003.

33. Wang KL, Liu CJ, Chao TF, Huang CM, Wu CH, Chen SJ, Yeh CM, Chen TJ, Lin SJ and Chiang CE: Sitagliptin and the risk of hospitalization for heart failure: A population-based study. Int J Cardiol 177: 86-90, 2014.

34. Weir DL, McAlister FA, Senthilselvan A, Minhas-Sandhu JK and Eurich DT: Sitagliptin use in patients with diabetes and heart failure: A population-based retrospective cohort study. JACC Heart Fail 2: 573-582, 2014. 